\title{
Effect of a satiating meal on the concentrations of procolipase propeptide in the serum and urine of normal and morbidly obese subjects
}

\author{
R C Bowyer, W M Rowston, A M T Jehanli, J H Lacey, J Hermon-Taylor
}

\begin{abstract}
The effect of a satiating meal on the serum and urinary concentrations of procolipase propeptide (Ala-Pro-Gly-Pro-Arg, APGPR) immunoreactivity, as measured by enzyme linked immunosorbent assay (ELISA) specific for free APGPR, has been studied in normal and morbidly obese human subjects. The normal subjects displayed a biphasic response with coordinate increases in both serum and urine APGPR immunoreactivity both occurring within the first two hours after the meal. In two of three of the morbidly obese subjects, this early rise in APGPR concentration in urine was not seen but was followed by a slow rise in urinary APGPR immunoreactivity at four to six hours. In both the normal and obese groups, the urinary immunoreactive signal was found to coelute with synthetic APGPR on gel chromatography. In rats, procolipase propeptide (Val-Pro-Asp-Pro-Arg, VPDPR) specifically inhibits fat intake early in the postprandial period when given peripherally or centrally. This study suggests that in humans APGPR reaches the circulation shortly after feeding and is excreted in the urine. These findings are consistent with the hypothesis that human procolipase propeptide may also act as a satiety signal. In addition the late appearance of the peptide in some of the morbidly obese patients could be associated with perturbation of appetite control in these subjects.
\end{abstract}

(Gut 1993; 34: 1520-1525)

Intestinal fat digestion occurs as a result of the combined action of lipase and colipase. ${ }^{1}$ Colipase is a heat stable, water soluble, non-enzymatic protein of molecular weight of about 10 kilo Daltons $(\mathrm{kDa}) .^{23}$ This cofactor is required for lipase activity in the presence of bile salts above the critical micelle concentration ${ }^{4}$ and acts by anchoring lipase in a one to one molar ratio to the bile salt emulsified triglyceride substrate. ${ }^{56}$ Colipase is secreted by the exocrine pancreas as the precursor, procolipase and its activation involves the tryptic cleavage of the $\mathrm{Arg}_{5}-\mathrm{Gly}_{6}$ bond releasing an $\mathrm{N}$-terminal pentapeptide. This procolipase propeptide has an amino acid sequence that seems to be highly conserved in nature with the sequence Val-Pro-Asp-Pro-Arg (VPDPR) in pig, ${ }^{8}$ ox,${ }^{9}$, rat, ${ }^{10}$ and horse ${ }^{11}$ and Ala-Pro-Gly-Pro-Arg (APGPR) in $\operatorname{man}^{12}$ and chicken. ${ }^{13}$ The sequence VPGPR has also been identified in the rat. ${ }^{14}$ This homology along with the finding that the genetically obese Zucker rat $(\mathrm{fa} / \mathrm{fa})$, in which obesity is characterised by profound hyperphagia, have a $60 \%$ reduction in their fasting pancreatic procolipase content compared with normal rats lead to the suggestion that the peptide might have a possible physiological role in appetite regulation. ${ }^{15}$

Further studies ${ }^{15}$ in Sprague-Dawley rats showed that intraperitoneal or intravenous injection of VPDPR changed the pattern but not the overall consumption of food with a reduced intake at the beginning and increased intake at the end of a four hour test period. This early 'satiating effect' was dose dependent and most marked at a dose of $40 \mu \mathrm{g}$ per animal, about equimolar to procolipase secretion during maximal stimulation with secretin and cholecystokinin (CCK). Addition of purified porcine procolipase, corresponding to $2 \mu \mathrm{g} / \mathrm{g}$ VPDPR after tryptic proteolysis, to the feed pellets of these rats lead to the loss of normal weight gain and maintenance of body weight. Once the normal diet was resumed, pellet consumption increased and weight gain returned to normal. Further studies showed that this effect on animal weight and pellet consumption was not seen with the addition of porcine colipase alone and that there was a significant reduction in total weight of food consumed at six hours when 10 $\mu \mathrm{g}$ synthetic VPDPR was given intraperitoneally. ${ }^{16}$ This second finding was confirmed by Shargill $e t a l^{17}$ although total consumption at 24 hours was unchanged with an intraperitoneal dose of $19 \cdot 6 \mu \mathrm{g}$.

Infusion of synthetic VPDPR $(16 \cdot 5-500 \mathrm{ng})$ into the third ventricle of conscious SpragueDawley rats over five minutes significantly reduced food intake from 30 minutes to six hours. At an effective dose of $16.5 \mathrm{ng}(33 \mathrm{pM})$, VPDPR is one of the more potent agents to inhibit food intake after injection into the third ventricle. ${ }^{17}$

A significant dose dependent reduction in fat consumption after intraperitoneal VPDPR administration was shown in Osborne-Mendel rats, a species susceptible to obesity on high fat diets but not low fat high carbohydrate diets. This effect lasted up to four hours with a dose of $20 \mu \mathrm{g}$ per animal but was prolonged for up to six hours with a dose of $40-80 \mu \mathrm{g}$ per animal. A compensatory increase in fat intake was seen after six hours and at 12 hours the total fat intake was the same as in the control group. ${ }^{18} \mathrm{~A}$ significant dose dependent reduction in fat intake was also shown with infusion of $100-400$ ng into the right lateral ventricle of SpragueDawley rats. ${ }^{19}$

The hypothetical action of VPDPR is that it is released from procolipase in the duodenum during digestion, is actively or passively 


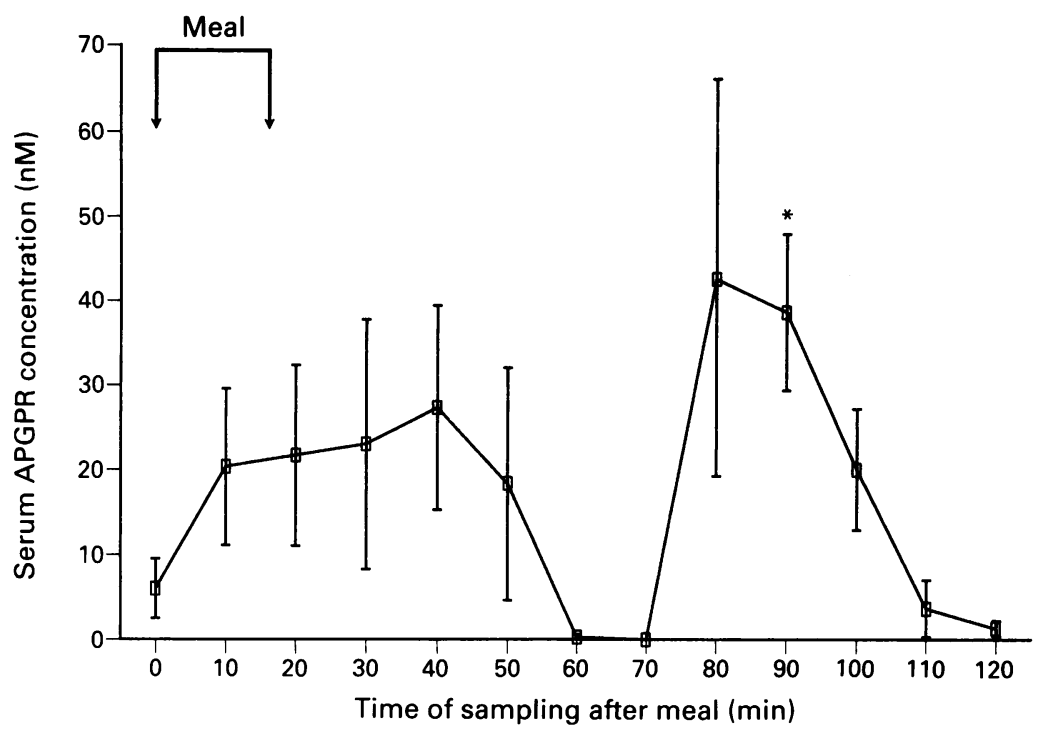

Figure 1: APGPR $n M$ in serum from normal healthy subjects $(n=6)$ before and after a satiating meal expressed as concentration $\mathrm{v}$ sampling time showing mean values (SEM) with samples $\left(^{\star}\right)$ differing significantly $(p<0.05)$ from both premeal samples.
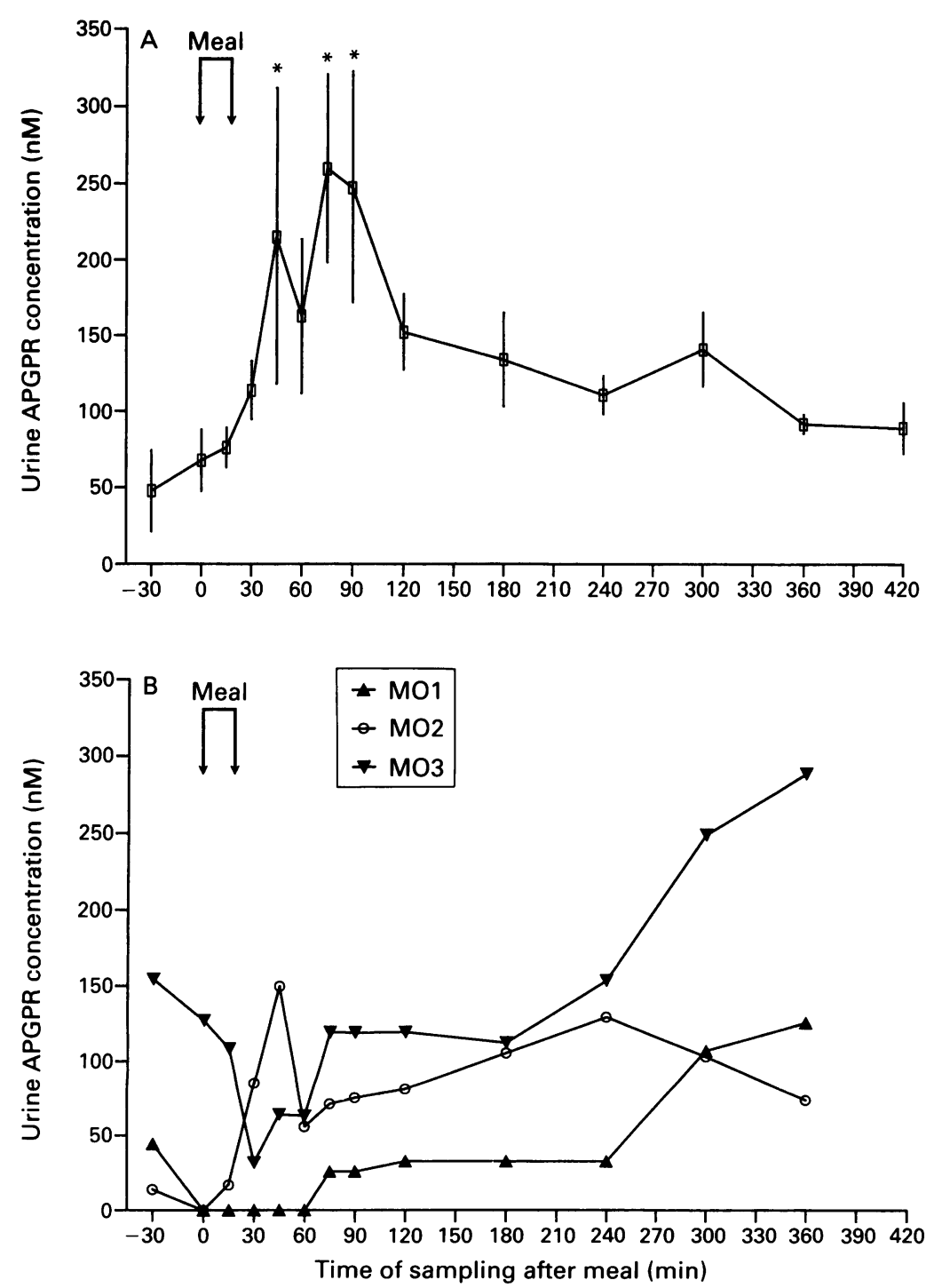

Figure 2: (A) APGPR $n M$ in urine from normal healthy subjects $(n=6)$ before and after a satiating meal expressed as concentration $\mathrm{v}$ sampling time showing mean values $(S E M)$ with samples $\left(^{\star}\right)$ differing significantly $(p<0.05)$ from both premeal samples; $(B) A P G P R n M$ in urine from three morbidly obese subjects $(M O 1-3)$ before and after a satiating meal expressed as urinary excretion $\mathrm{v}$ sampling time. absorbed, passes through the circulation to act on a receptor site in the central nervous system, and so inhibits, in the short term, further consumption of food, specifically that food which contains fat. At present, free VPDPR has not yet been shown to be absorbed into the circulation nor specific receptors in the central nervous system identified.

The effect of APGPR on satiation is more difficult to study in humans and has not so far been investigated. It is known, however, that synthetic APGPR has a very short half life $(<5$ minutes) in human serum in vitro but persists for up to four hours in human urine in vitro. ${ }^{20}$ This loss of immunoreactivity in serum and urine can be prevented by the addition of $20 \mathrm{mM}$ zinc acetate or by boiling for 10 minutes. This study was performed in an attempt to identify APGPR in blood after a satiating meal and to investigate the hypothesis that APGPR is absorbed into the circulation postprandially and may appear in urine. In addition, morbidly obese patients were studied to identify if there was any difference in the concentrations of the APGPR peptide in these subjects as this would be consistent with a pathophysiological role for APGPR in this group of disorders.

\section{Materials and methods}

SUBJECTS

This study was approved by the ethical committee of St George's Hospital Medical School and informed consent was obtained from all subjects. All chemical and biochemical reagents were obtained from Sigma (Poole, Dorset) or BDH (Dagenham, Essex) and were of analytical grade or of the highest purity available. Six healthy volunteers, (three men and three women), aged 27-38 years (mean $33 \cdot 2$ ) not known to have any pancreatic or other gastrointestinal diseases were studied. Their body mass index (BMI $)^{21} 22$ was in the normal healthy range of 20-25 (mean $22 \cdot 3$ ). The subjects completed written questionnaires: the Bulimia Investigatatory Test Edinburgh $(B I T E)^{23}$ and Eating Attitude Test (EAT) for anorexia nervosa ${ }^{24}$ scoring within the normal range $<19$ BITE symptoms (mean 2.33), <5 BITE severity (mean 1.33), <30 EAT (mean $2 \cdot 5)$. Similarly three morbidly obese female patients defined ${ }^{21}$ by having a BMI $>40$, aged $1 \%$ (MO1), 52 (MO2), and 70 (MO3) years, also not known to have any pancreatic or other gastrointestinal diseases were studied whose BMI were $41 \cdot 4,53 \cdot 4$, and $58 \cdot 1$. The subjects completed the BITE and EAT questionnaires with scores of 3 , 23 , and 30 (mean 18.7) for EAT, of 2, 22, and 24 (mean 17.7) for BITE symptoms and of 5, 6, and 4 (mean 5) for BITE severity.

EXPERIMENTAL PROCEDURES

The subjects were fasted over night having abstained from diuretic drugs - that is, alcohol and caffeine, the evening before. Two hours before a standard meal at $10 \mathrm{am}, 500 \mathrm{ml}$ of water was drunk. No further food or fluid was consumed, except for the standard meal until the last urine specimen had been collected. The meal 
consisted of $300 \mathrm{~g}$ 'Special Recipe' Muesli (W Jordan Ltd, Biggleswade, UK) and $300 \mathrm{~g}$ fresh pasteurised whole cows milk, the whole meal containing a total of $1191 \mathrm{kcal}, 43.3 \mathrm{~g}$ protein, $170.4 \mathrm{~g}$ carbohydrate, $41.7 \mathrm{~g}$ fat, $39 \mathrm{~g}$ fibre, and $305 \mathrm{~g}$ water. The meal was consumed as rapidly as was comfortable within 15 minutes or stopped when satiation occurred. The mean mass of meal consumed was $557 \mathrm{~g}$ for the normal and $308 \mathrm{~g}$ for the morbidly obese subjects. At 30 and 0 minutes before and at $15,30,45,60,75$, $90,120,180,240,300,360$, and 420 minutes after the onset of the meal, the subjects emptied their bladders, the volume of urine voided was recorded and $10 \mathrm{ml}$ urine immediately made 20 $\mathrm{mM}$ with zinc acetate. To minimise loss of APGPR immunoreactivity on storage, each urine sample was centrifuged at $3000 \mathrm{~g}$ for 20 minutes, the supernatant suspended in a boiling bath for 10 minutes, centrifuged for five minutes at $10000 \mathrm{~g}$, and the supernatant aliquoted and stored at $-20^{\circ} \mathrm{C}$ until assayed. Each subject had $5 \mathrm{ml}$ of blood sampled from a forearm vein immediately before and every 10 minutes for two hours after the onset of the meal. Each blood sample was immediately made $20 \mathrm{mM}$ with zinc
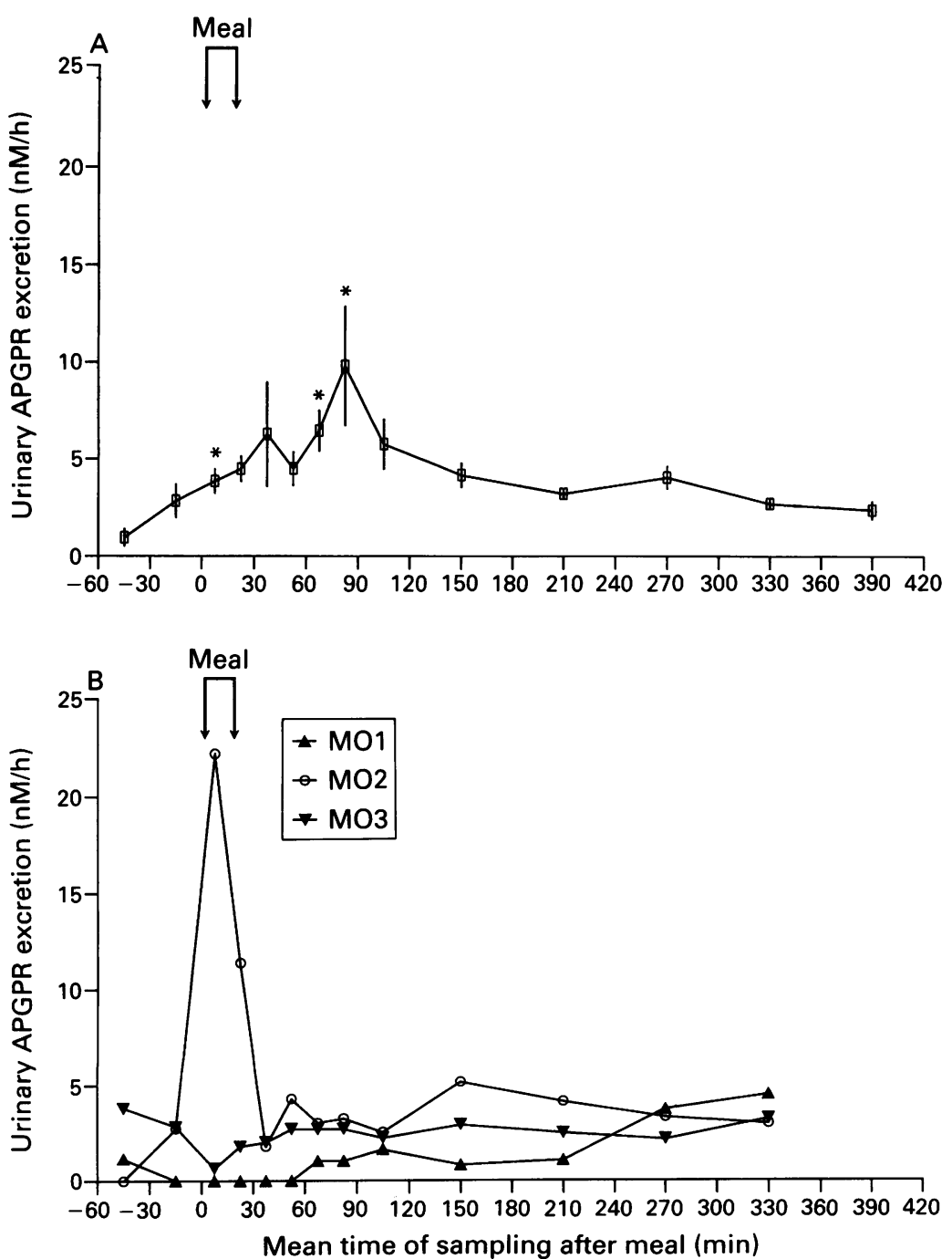

Figure 3: ( $A$ ) Urinary APGPR excretion from normal healthy subjects $(n=6)$ before and after a satiating meal expressed as concentration $\mathrm{v}$ midpoint in time of sampling period showing mean values $(S E M)$ with samples $(\star)$ differing significantly $(p<0.05)$ from both premeal samples; (B) Urinary APGPR excretion from three morbidly obese subjects (MO1-3) before and after satiating meal expressed as urinary excretion $\mathrm{v}$ midpoint in time of sampling period. acetate, allowed to clot, and within $2 \cdot 5$ hours of collection, centrifuged at $3000 \mathrm{~g}$ for 20 minutes, the separated serum mixed with an equal volume of ELISA immunoassay buffer containing 50 $\mathrm{mM}$ TRIS/HCL, $0.05 \%$ (wt/vol) casein, $3.1 \mathrm{mM}$ $\mathrm{NaN}_{3}, 10 \mathrm{mM}$ ethylenediaminetetra-acetic acid, $0.05 \%$ (wt/vol) Tween 20 at $\mathrm{pH} 7 \cdot 2-7 \cdot 4$, and suspended in a boiling bath for 10 minutes. Each sample was then centrifuged for five minutes at $10000 \mathrm{~g}$ and the supernatant labelled and stored at $-20^{\circ} \mathrm{C}$ until assayed.

The stored aliquots of urine and serum were later thawed at room temperature, thoroughly whirlmixed, centrifuged for five minutes at $10000 \mathrm{~g}$, and the supernatant assayed using the APGPR ELISA for free APGPR that we have previously described. ${ }^{20}$ All samples were assayed at a $50 \%$ dilution in immunoassay buffer and corrected for dilution after subtraction of the assay detection limit. Urinary APGPR excretion was calculated as a product of the urinary concentration for a given sample and the volume/ hour of urine output over that sampling period.

Two $7.5 \mathrm{ml}$ urine samples from one male subject at 75 and 90 minutes after the onset of the meal, collected and stored as previously described, were thawed at room temperature, pooled, lyophilised, and then reconstituted by mixing with $6 \mathrm{ml}$ distilled water. This pooled concentrated urine was then centrifuged at $10000 \mathrm{~g}$ for five minutes and $1 \mathrm{ml}$ of supernatant chromatographed on a Sephadex G-25 column $(0.9 \times 43 \mathrm{~cm})$ in TRIS buffered saline (TBS) containing $50 \mathrm{mM}$ TRIS/ $\mathrm{HCl}, 0.15 \mathrm{M} \mathrm{NaCl}$, $3.1 \mathrm{mM} \mathrm{NaN}_{3}$ at $\mathrm{pH} 7 \cdot 3$ at a flow rate of $39.5 \mathrm{ml}$ hour and $1.056 \mathrm{ml}$ fractions collected and assayed using the APGPR ELISA. Similarly, three $8 \mathrm{ml}$ urine samples collected at 240,300 , and 360 minutes after the onset of the meal from the third morbidly obese subject were pooled, lyophilised, and reconstituted as before with $6 \mathrm{ml}$ distilled water. The resultant pooled concentrated urine was centrifuged and $1 \mathrm{ml}$ chromatographed and assayed as before. The chromatography column was calibrated using synthetic APGRP in $50 \mathrm{mM}$ TRIS buffered saline and the fractions assayed for APGPR.

\section{STATISTICAL ANALYSIS}

The results of sequential APGPR propeptide assay of urine and serum were analysed using the Wilcoxon matched pairs signed ranks test and the urinary APGPR concentrations and excretion from normal and morbidly obese groups analysed using the Kruskal-Wallis one way analysis of variance (ANOVA).

\section{Results}

\section{APGPR CONCENTRATION IN SERUM}

In the normal subjects the fasted mean serum APGPR concentration was at the detection limit of the assay but postprandially two peaks of APGPR immunoreactivity were seen in the first and second hours after the start of the meal (Fig 1). Only the peak at 90 minutes, however, achieved a significant difference $(p<0.05)$ from the premeal value. No APGPR was detected in 


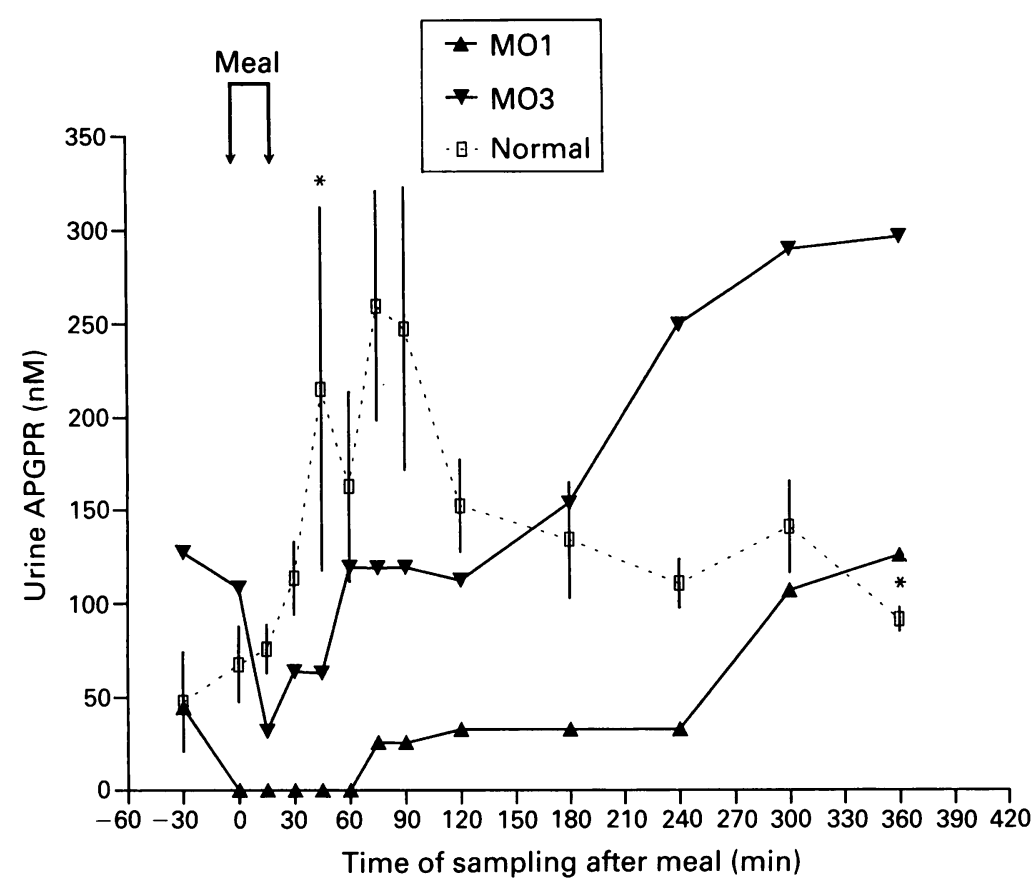

Figure 4: APGPR $n M$ in urine from normal healthy subjects $(n=6)($ mean $(S E M))$ and from two morbidly obese subjects $(M O 1, M O 3)$ before and after a satiating meal $\left({ }^{\star}\right)$ differing significantly $(p<0.05)$ from the morbidly obese samples at any given time.

any of the serum samples from the three morbidly obese patients while fasted or after the test meal.

APGPR CONCENTRATION AND EXCRETION IN URINE In the normal subjects (Fig 2A), the APGPR concentrations in urine increased after the test meal and again two peak mean values of APGPR immunoreactivity were seen in the first and second hours at 45 and 75 minutes after the start of the meal corresponding in time with the peaks of serum APGPR found in the normal subjects. These peaks were both significantly different from the premeal values $(p<0.05)$. In the obese subjects (Fig 2B) there was no significant overall increase in urinary APGPR concentration after the meal and there was no significant difference between the urinary APGPR concentration at any given time postprandially between the morbidly obese and normal groups. In the first and third obese subjects (MO1 and MO3), however, the total urinary APGPR concentration slowly increased towards the end of the sampling period, four to six hours after the onset of the meal.

Urinary APGPR excretion (Fig 3A) in the normal group increased to a peak mean value at 82.5 minutes after the start of the meal and was significantly increased at $7 \cdot 5,67 \cdot 5$, and 82.5 minutes compared with the fasted values. In the obese subjects the total urinary APGPR excretion showed no significant overall increase (Fig $3 \mathrm{~B})$ although in the second obese subject (MO2) the APGPR excretion in urine was similar to that seen in normal subjects - that is, an early peak within the first two hours after the onset of the meal. Again there was no significant difference between the morbidly obese and normal group's urinary APGPR excretion at any given time postprandially. Figure 4 shows a comparison of the APGPR urine concentrations between the normal subjects and $\mathrm{MO}$ and $\mathrm{MO} 3$ emphasising the differing appearance of the immunoreactive signal between these two groups. The significant difference at 45 and 360 minutes postprandially between the results in the normal and these two morbidly obese subjects cannot be accounted for by a difference in the urine output (one way ANOVA, $p>0.05)$. A similar difference in urinary APGPR excretion postprandially was seen between the normal subjects and $\mathrm{MOl}$ and MO3 and was significant at 15,30 , and 45 minutes after the start of the meal (data not shown).

\section{CHROMATOGRAPHY OF URINARY APGPR}

Assay of fractions of pooled and lyophilised urine from the second APGPR immunoreactivity peak from one of the normal male subjects clearly showed that the immunoreactive signal coeluted with synthetic APGPR suggesting that the immunoreactive peak was principally a result of the native peptide (Fig 5A). Finally chromatography and assay of the lyophilised late pooled urine APGPR peak in the third morbidly obese subject again confirmed that the main immunoreactive signal comigrated with APGPR (Fig 5B).

\section{Discussion}

The N-terminal pentapeptide of pancreatic procolipase is highly conserved in nature with only three forms found to occur in the higher vertebrates, VPDPR, VPGPR, and the APGPR form found in humans and chickens. This homology is not confined only to the kinking proline residues and the long basic side chain of arginine but also includes the hydrophobic amino terminal valine or alanine. VPDPR has been shown to have two possible physiological functions besides its role as a propeptide. Firstly it has been shown to act specifically to inhibit dietary fat consumption over a period of four to six hours after experimental administration without changing total 24 hour intake. Secondly this peptide has been recently shown significantly to inhibit pancreatic protein secretion after intraduodenal infusion in pigs. ${ }^{25}$ If this peptide plays a significant part in regulating fat consumption, it is interesting to note that dietary fat has a role in colipase regulation with an adaptive response to dietary lipids having been shown with at least a twofold increase in pancreatic procolipase in rats fed a $25-30 \%$ lipid containing diet. ${ }^{26}$ This may form the basis of a negative feed back loop with increased fat intake leading to increased procolipase secretion, increased VPDPR release during digestion culminating in early satiety for dietary fat and a reduction in its consumption.

This study shows that in humans APGPR rapidly appears in the circulation in response to a satiating meal and does so in a biphasic manner. Transmucosal transport of the intact oligopeptide may be by the paracellular pathway associated with changes in tight junction structure that accompany $\mathrm{Na}^{+}$-glucose activated absorption. ${ }^{27}$ The reason for the biphasic peaks of APGPR in serum is not clear but may come about as a result 

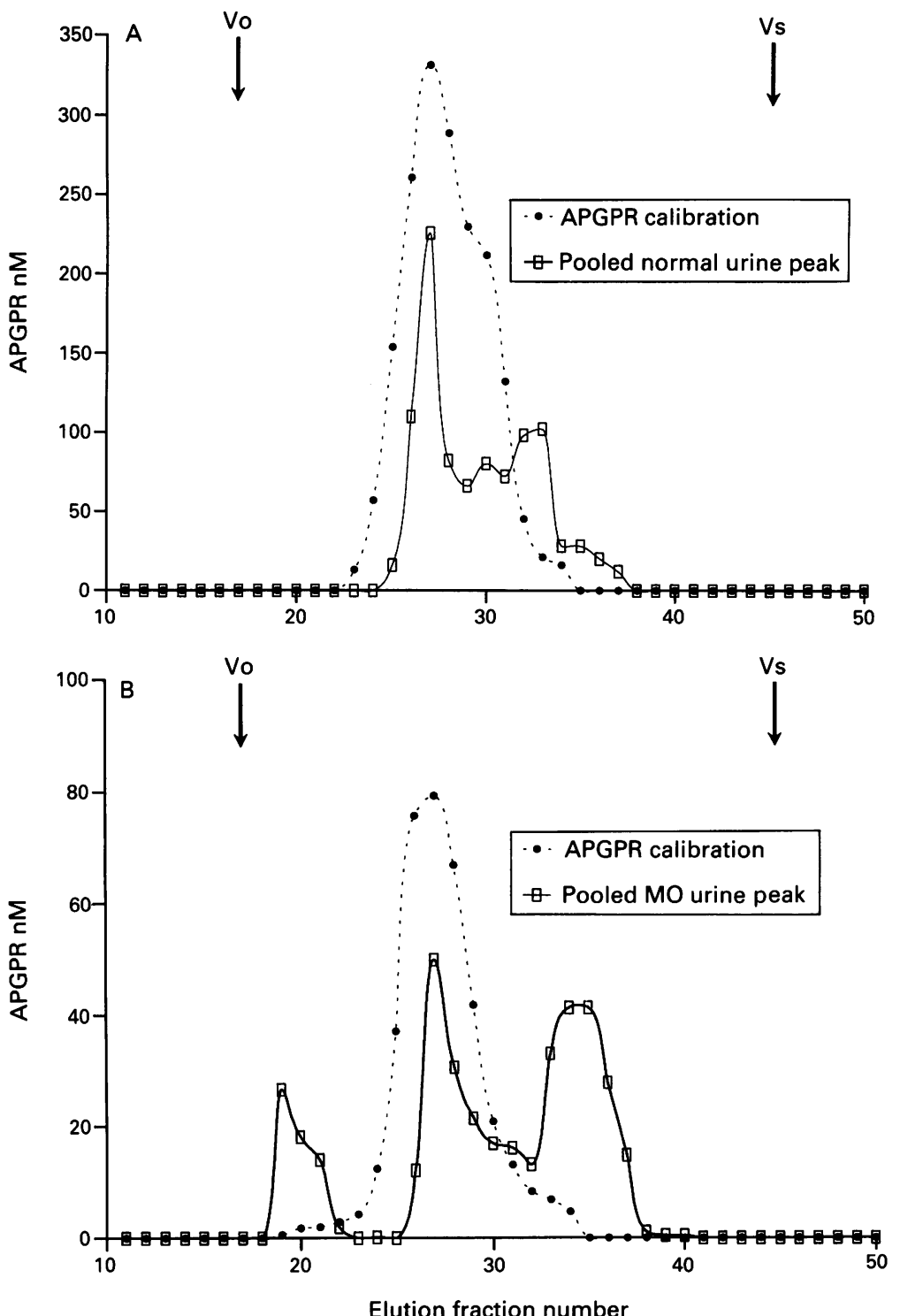

Figure 5: (A) Sephadex G-25 chromatography of lyophilised $(\times 2 \cdot 5)$ pooled urine from the 75 and 90 minute peak of immunoreactivity after the start of a satiating meal taken from one normal male subject showing results of APGPR assay of fractions; $(B)$ Sephadex $G-25$ chromatography of lyophilised $(\times 4)$ pooled urine from the late $240,300,360$ minute peak of immunoreactivity after the start of a satiating meal taken from MO3 showing results of $A P G P R$ assay of fractions (volume $=1.056 \mathrm{ml}, \mathrm{VO}=$ void volume, $V \mathrm{~s}=$ salt peak).

of two phases of pancreatic procolipase secretion corresponding to early, cephalic, vagally mediated pancreatic secretion of low volume but rich in pancreatic enzymes ${ }^{28}$ followed by a duodenal phase in response to CCK and secretin as acidified, partially digested food enters the duodenum. ${ }^{29}$ In addition, the appearance of APGPR in serum was mirrored by its detection in urine suggesting not only that the peptide can survive immunoreactively intact in the circulation for a sufficient time to allow systemic dispersal but also is rapidly excreted by the kidney. It was not possible to confirm that the immunoreactive signal in serum was due to APGPR but the immunoreactive signal in urine coeluted with synthetic APGPR. These results are consistent with the hypothesis that human APGPR might act, similarly to VPDPR, as a satiety signal.

In two of the three morbidly obese subjects, there was an absence of the early urinary APGPR immunoreactivity peaks in concentration and excretion and only a slow rise in urinary APGPR concentration at four to six hours. If APGPR were a satiety signal and the urine concentrations mirrored circulating blood concentrations, then the late appearance of APGPR in the circulation could explain the loss of appetite control in these morbidly obese patients. Whether this abnormal response to the meal in these morbidly obese subjects is as a result of an intrinsic abnormality or is a consequence of pancreatic hypofunction seen in the morbidly obese ${ }^{30}$ is unclear. Larger numbers of subjects need to be studied to determine the significance of these preliminary findings.

This research was supported by grants from the Medical Research Committee of St George's Hospital and the South West Thames Regional Health Authority.

The data describing detection of APGPR postprandially in The data describing detection of APGPR postprandially in
normal subjects have previously been published in abstract form normal subjects have previous
in Digestion $1991 ; 49: 10-1$.

1 Borgström B, Erlanson-Albertsson C. Pancreatic colipase. In Borgström B, Brockman HL, eds. Lipases. Amsterdam Elsevier Science, 1984: 151-83.

2 Lee PC. Comparative studies of canine colipase and lipases from bovine, porcine, canine, human and rat pancreases. Comp Biochem Physiol [B] 1978; 60: 373-8.

3 Sternby B, Larsson A, Borgström B. Evolutionary studies on pancreatic colipase. Biochim Biophys Acta 1983; 750: 340-5.

4 Borgström B, Erlanson C Pancreatic juice colipase: physiological importance. Biochim Biophys Acta 1971;242: 509-13.

logical importance. Biochim Biophys Acta 1971; 242: 509-13. onnér J, Spink CH, Borgström B, Sjohöm I. Interaction between pancreatic lipase, co-lipase, and taurodeoxycholate
in the absence of triglyceride substrate. Biochemistry 1976; in the absence

6 Patton JS, Albertsson PA, Erlanson C, Borgström B. Binding of porcine pancreatic lipase and colipase in the absence of substrate studies by two-phase partition and affinity chromatography. $\mathcal{F}$ Biol Chem 1978; 253: 4195-202.

7 Borgström B, Wieloch T, Erlanson-Albertsson C. Evidence for a pancreatic pro-colipase and its activation by trypsin. FEBS Lett 1979; 108: 407-10.

8 Erlanson C, Fernlund P, Borgström B. Purification and characterization of two proteins with colipase activity from porcine pancreas. Biochim Biophys Acta 1973; 310:437-45.

9 Rathelot J, Julien R, Canioni P, Sarda L. Isolation and partial characterization of bovine pancreatic colipase. Biochimie 1975; 57: 1123-30.

10 Erlanson-Albertsson $C$. The existence of pro-colipase in pancreatic juice. Biochim Biophys Acta 1981; 666: 299-300.

11 Julien R, Rathelot J, Canioni P, Sarda L, Grégoire J, Rochat H. Horse pancreatic colipase: isolation by a detergent method and amino terminal sequence of the polypeptide chain. Biochimie 1978; 60: 103-7.

12 Sternby B, Borgström B. One-step purification of procolipase from human pancreatic juice by immobilized antibodies against human colipase 86 . Biochim Biophys Acta 1984; 786 : 109-12.

13 Bosc-Bierne I, Rathelot J, Bechis G, Delori P, Sarda L. Evidence for the existence of procolipase in chicken pancreas and pancreatic juice. Biochimie 1984; 66: 413-6.

14 Wicker C, Puigserver A. Rat pancreatic colipase mRNA: Nucleotide sequence of a cDNA clone and nutritional regulation by a lipidic diet. Biochem Biophys Res Commun regulation by a $1990 ; 167: 130-6$.

15 Erlanson-Albertsson C, Larsson A. The possible physiological function of pancreatic pro-colipase activation peptide in appetite regulation. Biochimie 1988 ; 70 : 1245-50.

16 Erlanson-Albertsson C, Larsson A. The activation of peptide of pancreatic procolipase decreases food intake in rats. Regul Pept 1988; 22: 325-31.

17 Shargill NS, Tsujii S, Bray GA, Erlanson-Albertsson C Enterostatin suppresses food intake following injection into the third ventricle of rats. Brain Res 1991; 544: 137-40.

18 Okada S, York DA, Bray GA, Erlanson-Albertsson C. Enterostatin (Val-Pro-Asp-Pro-Arg), the activation peptide of procolipase, selectively reduces fat intake. Physiol Behav 1991; 49: 1185-9.

19 Erlanson-Albertsson C, Mei J, Okada S, York D, Bray GA. Pancreatic procolipase propeptide, enterostatin, specifically
inhibits fat intake. Physiol Behav 1991; 49: 1191-4.

20 Bowyer RC, Jehanli AMT, Patel G, Hermon-Taylor J. Development of enzyme-linked immunosorbent assay for Development of enzyme-linked immunosorbent assay for
free human pro-colipase activation peptide (APGPR). Clin free human pro-colipase activ

21 Bray GA. Overweight is risking fate. Definition, classification prevalence, and risks. Ann N Y Acad Sci 1987; 499: 14-28.

22 Garrow JS. Obesity and related diseases. Edinburgh: Churchil Livingstone, 1988: 1-19.

23 Henderson M, Freeman CP. A self-rating scale for bulimia. The 'BITE'. Br f Psychiatry 1987; 150: 18-24.

24 Garner DM, Garfinkel PE. The eating attitudes test: an index of the symptoms of anorexia nervosa. Psychol Med 1979; 9 273-9.

25 Erlanson-Albertsson C, Weström B, Pierzynowski S, Karlsson 
S, Ahren B. Pancreatic procolipase activation peptide enterostatin - inhibits pancreatic enzyme secretion in the pig. Pancreas 1991; 6: 919-24.

26 Wicker C, Puigserver A. Effects of inverse changes in dietary lipid and carbohydrate on the synthesis of some pancreatic secretory proteins. Eur $\mathcal{F}$ Biochem 1987; 162: 25-30.

27 Atisook K, Madara JL. An oligopeptide permeates intestinal tight junctions at glucose-elicited dilations. Implications for tight junctions at glucose-elicited dilations. Implications for
oligopeptide absorption. Gastroenterology 1991; 100: 719-24.
28 Sarles H, Dani R, Prezelin G, Souville C, Figarella C. Cephalic phase of pancreatic secretion in man. Gut 1968; 9: 214-21.

29 Gaskin KJ, Durie PR, Hill RE, Lee LM, Forstner GG. Colipase and maximally activated pancreatic lipase in normal subjects and patients with steatorrhoea. $\mathcal{F}$ Clin Invest 1982; 69: 427-34.

30 Wisén $\mathrm{O}$, Rössner S, Johansson C. Impaired pancreaticobiliary response to vagal stimulation and to cholecystokinin in human obesity. Metabolism 1988; 37: 436-41. 